\title{
Corrosion Damage of Aluminum Alloy in Unsymmetric Uimethyl Hydrazine and Dinitrogen Tetroxide Liquid Propellant
}

\author{
Youhong ZHANG ${ }^{\mathrm{a}}$, Xinlong $\mathrm{CHANG}^{\mathrm{b}}$ and Wanlei $\mathrm{LIU}^{\mathrm{c}}$ \\ Xian Research Inst of Hitech, Xian 710025, China. \\ ayhnpu@163.com¹, ${ }^{\mathrm{a}}$ changxl123@163.com, ${ }^{\mathrm{c}}$ wanleiliu1@sina.com
}

\begin{abstract}
The high strength aluminum alloy double cantilever beam (DCB) specimens were corroded under the conditions of different liquid propellant environment. After the stress corrosion exposure, the scanning electron microscopy and energy-dispersal analyses on corrosion damage were carried out. The corrosion damage sensitivity and the stress corrosion character of the LD10 high strength aluminum alloy in $\mathrm{N}_{2} \mathrm{O}_{4}, \mathrm{UDMH}$ and $3.5 \% \mathrm{NaCl}$ corrosion solution were analyzed.
\end{abstract}

\section{Introduction}

LD10 aluminum alloy had been frequently used in the manufacture of complex forgings and pressure vessels used for liquid propellant stockpile [1, 2]. The Unsymmetric Dimethyl Hydrazine (UDMH) and Dinitrogen Tetroxid $\left(\mathrm{N}_{2} \mathrm{O}_{4}\right)$ are the two popular kinds of liquid propellant and used in the field of carrier rocket, torpedo, attitude control equipment, orbit control and so all. Due to the corrosive, inflammable, explosive and high toxicity character of $\mathrm{UDMH}$ and $\mathrm{N}_{2} \mathrm{O}_{4}$, the service and storage environment is very critical [3]. When the pressure vessels made in LD10 aluminum alloy are used for storing $U D M H$ and $\mathrm{N}_{2} \mathrm{O}_{4}$, it does not only need to endure the corrosion of propellant and other environments, but also shall stand the stress in the service procedure. The comprehensive effects of corrosive environment and stress will impact the reliability and quality of the aluminum alloy structures $[4,5]$. It is necessary to study the SCC character of the aluminum alloy served in liquid propellant environment, however, because of the hypertoxic character of UDMH and $\mathrm{N}_{2} \mathrm{O}_{4}$, the SCC experiment is very dangerous. So, there are still no SCC experiment reports in UDMH and $\mathrm{N}_{2} \mathrm{O}_{4}$ environment, and there are only limited documents about of the material corrosion study in liquid propellant environment.

This paper presented the experimental study on the corrosion damage and SCC behaviors on LD10 aluminum alloy structure. A preliminary analytic conclusion, which consists of corrosion damage configuration, corrosion evolution rhythm and corrosion crack growth was proposed.

\footnotetext{
* Corresponding author: zyhnpu@163.com
} 


\section{Experimental Work}

The material used in this investigation was LD10 high strength aluminum alloy supplied in the form rolled plate ( $19 \mathrm{~mm}$ thickness value). The $\mathrm{wt} \%$ composition of the studied alloy was $4.30 \mathrm{Cu}, 0.90 \mathrm{Si} 0.70 \mathrm{Mg}, 0.60 \mathrm{Mn}, 0.50 \mathrm{Fe}, 0.30 \mathrm{Zn}, 0.15 \mathrm{Ti}$, and $\mathrm{Al}$ (balance).

The alclad was machined out from the LD10 aluminum alloy plate, and then the double cantilever beam (DCB) specimens were made and the initial crack was made used the wire discharge machining according to ASTM G47. Fig. 1 shows the specimen equipment. Based on the statistical loading method, the fatigue crack was prefabricated using a closed loop servohydraulic testing machine.

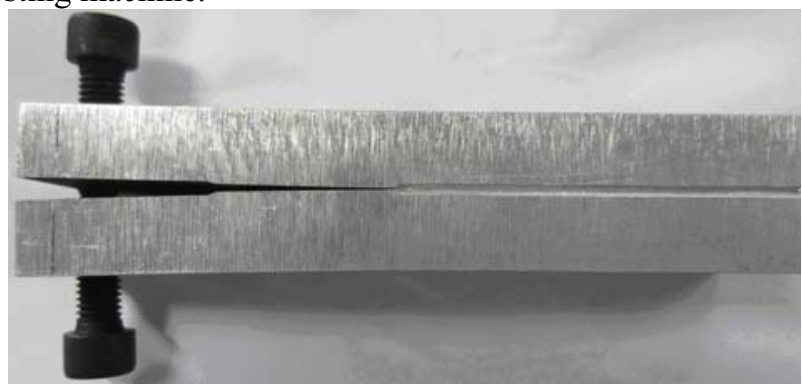

Fig.1 The specimen map

The specimens were subjected to a constant amplitude cyclic loading with a maximum tensile stress of $7.5 \mathrm{KN}$ and a stress ratio of $\mathrm{R}=0.1$ at a frequency of $10 \mathrm{~Hz}$. The length of prefabricating crack is $2.0-2.5 \mathrm{~mm}$ and the realistic crack length can be given from the optical microscope.

The DCB specimens (shown as Fig.1) which can self load was used in the experiment, and this specimen equipment uses the bolt to provide the loading force. The specimen equipment has the advantage of compact structure and easy to carry out the exposure corrosion experiment in high toxicity liquid propellant environment.

In the experiment, the optical microscope was used to measure the open distance of the specimen's notch. Before loading, the specimen notch was washed by the ethanol, and the bolt was smeared a thin flat of petrolatum. The back-end of the specimen was fastened, and the specimen was loaded to the anticipative displacement. The initial surface crack length was measured by the optical microscope.

The DCB specimens with pre-crack were put in to three solutions that were $3.5 \% \mathrm{NaCl}$, $\mathrm{N}_{2} \mathrm{O}_{4}$ and UDMH. Every component contains three specimens, and the main ion composition of the three solutions was listed in Table1.

TABLE 1 THE MAIN ION COMPOSITION OF DIFFERENT SOLUTIONS

\begin{tabular}{cc}
\hline Corrosion solutions & Main ion composition \\
\hline $\mathrm{N}_{2} \mathrm{O}_{4}$ & $\mathrm{H}^{+} 、 \mathrm{NO}_{3}{ }^{-}$ \\
$\mathrm{UDMH}$ & $\mathrm{NH}_{4}{ }^{+}, \mathrm{CO}_{3}{ }^{2-}$ \\
$3.5 \% \mathrm{NaCl}$ & $\mathrm{Na}^{+}, \mathrm{Cl}^{-}$ \\
\hline
\end{tabular}

Because of high toxicity character of UDMH and $\mathrm{N}_{2} \mathrm{O}_{4}$, in the mean time, in the procedure of SCC experiment, the experiment workers need work long time in UDMH and $\mathrm{N}_{2} \mathrm{O}_{4}$ environment, the necessary protective measures are needed. In the procedure of SCC experiment, the experiment workers need dress the T1mask gas mask and polypropylene protective gloves.

The SCC experiment procedure was provided as follows: at first, the three components (including 3 specimens) of was loaded to anticipated values of stress intensity factor. The 
stress intensity factor values of three components are briefly 750,800 and $830 \mathrm{MP}_{a} \cdot \mathrm{mm}^{1 / 2}$. Secondly, the loaded DCB specimens were put into three solutions which were $3.5 \% \mathrm{NaCl}$, $\mathrm{N}_{2} \mathrm{O}_{4}$ and UDMH. The SCC experiment was carried out in closed container, the notch face of the specimen is up, and the corrosion liquid level is higher than the pre-machined fatigue crack and lower than the loading bolt. The specimen was taken out from the closed container every 15 days and the values of crack length are read from the optical microscope. At last, the experiment was terminated until the situation of no crack propagation was observed, then, after the experiment, the specimen was taken out and the final crack length was recorded and calculated out the values of the initial stress intensity factor.

\section{Results and Discussion}

After the SCC experiment, the DCB specimens were taken out from the three components solution, and the corrosion damage configuration and evolution are observed. The corrosion damage configurations of the specimens in the three kinds of solution are shown in Fig.2.

To the specimens in $3.5 \% \mathrm{NaCl}$ solution, at the surface of the specimen, there are a mount of crystal, and surface layer exfoliating, a great deal of little corrosion pits. To the specimens in $\mathrm{N}_{2} \mathrm{O}_{4}$ solution, the surface of the specimens covered a layer of hoarfrost, and after cleaning out using distilled water, the specimens surface appear large piece of yellow substance. At part of the surface, there are breaken off corrosion production. To the specimens in UDMH solution, the surface of the specimens covered a layer of white corrosion production.

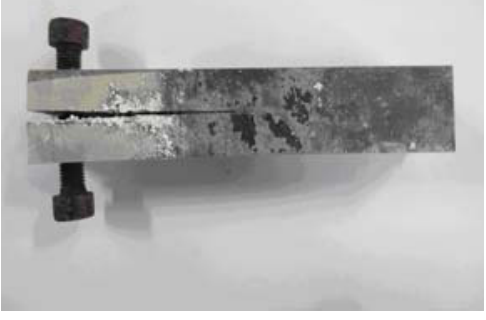

a. Surface corrosion configuration of the specimen in $3.5 \% \mathrm{NaCl}$ solution

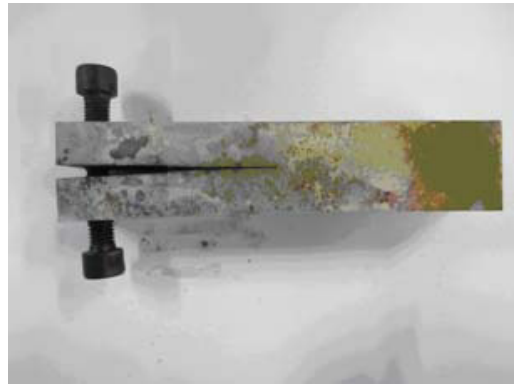

b. Surface corrosion configuration of the specimen in $\mathrm{N}_{2} \mathrm{O}_{4}$ 


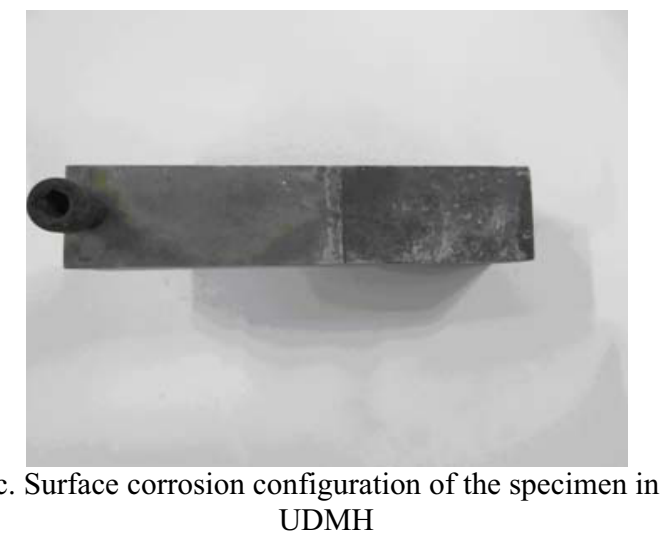

Fig.2 Surface corrosion configuration of the specimen in different solution

The particular corrosion damage configuration analyses were performed on the surfaces of specimens using a scanning electron microscope (SEM). The SEM corrosion damage photos are shown in Fig.3.

As can be seen in Fig.3, it is different of the surface corrosion damage degree in different solution, the corrosion degree of the specimen in $3.5 \% \mathrm{NaCl}$ solution is the most serious, it can be seen on the surface that there are chap configuration, corrosion cast, and darker color. To the specimen in $\mathrm{N}_{2} \mathrm{O}_{4}$, on the surface, there are little asymmetry yellow speckle, there are chap configuration and corrosion cast in part. To the specimen in UDMH, there are not obvious change on the surface, the color of specimen immerging in UDMH is more shining, it seem as was bashed by oil.

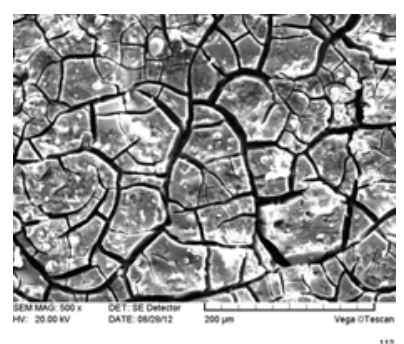

a. Corrosion damage sensitivity of the specimens in $3.5 \% \mathrm{NaCl}$ solution

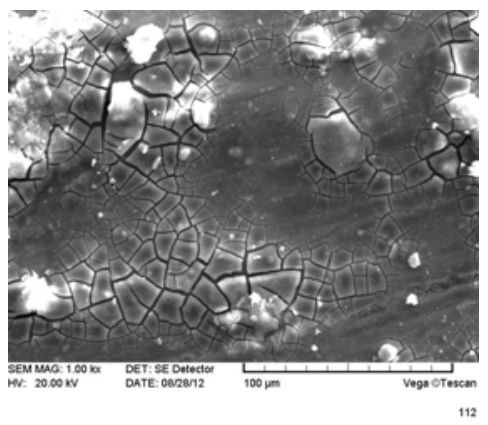

b. Corrosion damage sensitivity of the specimens in $\mathrm{N}_{2} \mathrm{O}_{4}$ solution 


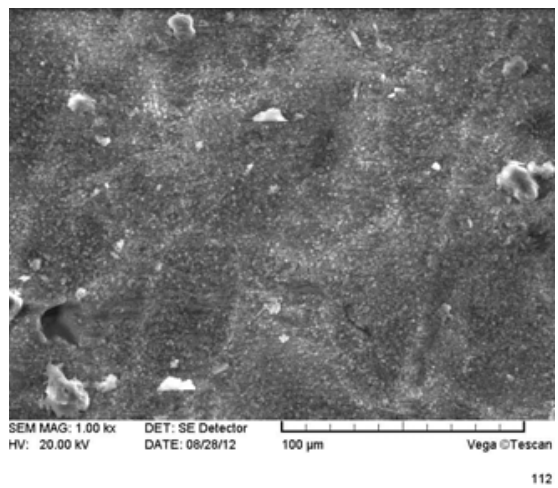

c. Corrosion damage sensitivity of the specimens in UDMH solution

Fig.3 The SEM analysis of surface corrosion figuration in different solution

In $3.5 \% \mathrm{NaCl}$ solution and $\mathrm{N}_{2} \mathrm{O}_{4}$, the corrosion damage course of LD10 aluminum alloy contains corrugating, chaping, breaking off and becoming corrosion pits. The energy spectrum analysis was carried out on the corroded LD10 aluminum alloy and the pristine LD10 aluminum alloy material, the element content of the corrosion production of the LD10 aluminum alloy in different corrosive environment were listed in table2.

TABLE2 ELEMENT CONTENT OF THE CORROSION PRODUCTION (ATOM\%)

\begin{tabular}{ccccccccc}
\hline element & $\mathrm{Al}$ & $\mathrm{Mg}$ & $\mathrm{Si}$ & $\mathrm{Mn}$ & $\mathrm{Fe}$ & $\mathrm{Cu}$ & $\mathrm{O}$ & $\mathrm{Cl}$ \\
\hline pristine & 94.71 & 0.54 & 1.27 & 0.60 & 0.24 & 2.63 & - & - \\
$3.5 \% \mathrm{NaCl}$ & 63.13 & - & - & 0.48 & - & 0.56 & 34.89 & 0.94 \\
$\mathrm{~N} 2 \mathrm{O} 4$ & 48.01 & - & 36.57 & 0.26 & 1.06 & 1.25 & 12.61 & - \\
$\mathrm{UDMH}$ & 86.22 & 0.76 & 1.46 & 0.66 & - & 4.33 & 6.58 & - \\
\hline
\end{tabular}

As can be seen in Table2, only the specimen immersed in $3.5 \% \mathrm{NaCl}$ solution contains the $\mathrm{Cl}$ ion, and the corrosion production of the rest specimens mainly contains oxygen element. It shows that the main chemistry reaction is oxidation behavior.

\section{Conclusions}

The surface corrosion damage degree in different solution is different, and the corrosion degree of the specimen in $3.5 \% \mathrm{NaCl}$ solution is the most serious. To the specimen in $\mathrm{N}_{2} \mathrm{O}_{4}$, on the surface, there are little asymmetry yellow speckle, there are chap configuration and corrosion cast in part. To the specimen in UDMH, there are not obvious change on the surface, the color of specimen immerging in UDMH is more shining.

\section{References}

1. W. L. Liu, X. L. Chang, Y. H. Zhang, J. W. Lai, The mechanism and research method of aluminum alloy stress corrosion, Corro Sci and Pro Tech. 25 (2013) 71-73.

2. Y. H. Wang, H. J. Chen, Stress corrosion and preventive measures of launch vehicle pipeline, Missil Spa Vehi. 1(2005) 44-49. 
3. X. L. Chang, W. L. Liu, J. W. Lai, Y. H. Zhang, Stress corrosion cracking susceptibility of LD10 aluminum alloy, J. Chinese Soc Corro and Pro. 33 (2013) 347-350.

4. B. Cho, A. Chudnovsky, R. Paradkar etc, Experimental and theoretical investigation of stress corrosion crack(SCC) growth of polyethylene pipes. Poly Degra and Stab, 94 (2009) 859-867.

5. D. Shaisg, S. B. Newcomb, The influence of microstructure on the formation of stress corrosion cracks in 7XXX series aluminum alloys, Mater Sci Forum, 331 (2000) 1635-1640. 